Author's post-print: I. Indacoechea-Vega, P. Pascual-Muñoz, D. Castro-Fresno, D. Zamora-Barraza. “Durability of geothermal grouting materials considering extreme loads". Construction and Building Materials 126 (2018), 732-739. ISSN: 0950-0618. DOI: 10.1016/j.conbuildmat.2017.12.072.

\title{
Durability of geothermal grouting materials considering extreme loads
}

\author{
I. Indacoechea-Vega ${ }^{a^{*}}$, P. Pascual-Muñoz ${ }^{b}$, D. Castro-Fresno ${ }^{c}$, D. Zamora-Barraza ${ }^{d}$ \\ ${ }^{a}$ GITECO Research group, Universidad de Cantabria, 39005, Santander, Spain. Email: indacoecheai@unican.es \\ - Tel: (+34) 9422039 43; Fax: (+34) 942201703 \\ ${ }^{\mathrm{b}}$ GITECO Research group, Universidad de Cantabria, 39005, Santander, Spain. Email: pascualmp@unican.es \\ c GITECO Research group, Universidad de Cantabria, 39005, Santander, Spain. Email: castrod@unican.es \\ ${ }^{d}$ School of Construction Engineering, Universidad Católica del Maule, Talca, Chile. Email: dzamora@ucm.cl
}

\section{Abstract}

The concern about the massive use of the non-renewable and very limited fossil fuels together with the well-known effects of the global warming makes it more necessary the efficient use of the current forms of renewable energy generation. Because of the crucial role played by the grouting materials in the Ground Source Heat Pumps (GSHP), a proper selection of these elements should be made based on a deep knowledge of their performance. In this paper, thermal conductivity, mechanical strength and grout-pipe permeability of four different highly workable grouts have been tested before and after they were subjected to wet-dry and freezethaw durability treatments. Results obtained demonstrated the harmful effects of using a large amount of mixing water in grouts subjected to those extreme loads. However, the use of these type of grouts with very good workability is still possible in GSHP installations with balanced thermal designs provided that regular operational and environment conditions are considered.

Keywords: ground source heat pump, grouting material, thermal conductivity, mechanical performance, permeability, durability.

\section{Introduction}

Around $40 \%$ of the worldwide energy is consumed to provide buildings with lighting, heating or cooling [1]. Today, many of the systems used to supply all these services are not as efficient as would be desired and cause the emission of greenhouse gases (GHGs) into the atmosphere. However, the environmental consciousness and awareness of the actual impact is growing in the last few years. The shallow geothermal energy systems or ground source heat pumps (GSHP) are becoming more and more popular as one of the most efficient forms of renewable energy. Through these systems, the heat is exchanged with the ground by means of a pumped water/glycol fluid that flows through a buried pipe. Between the pipe and the ground, a grouting 
63. Different cement-based grouts were also subjected to tests that determined their hydraulic and

material is needed that provides the borehole with essential properties. In summer time, the sensible heat from the water/glycol fluid is transferred by convection and conduction through the pipe wall (radiation can be neglected) and then by conduction through the grout until the grout/ground interface, from which the heat is transferred to the ground mostly by conduction. When pipe-grout and grout-ground contacts are not good enough, the convection process in these interfaces becomes more important. In winter time, the heat moves in the opposite direction by means of the same heat exchange mechanisms. From the environmental point of view the proper sealing provided by the grout would act as a hydraulic barrier along the borehole to avoid cross-contamination of different aquifers and transport of surface contaminants to aquifers. Furthermore, a high pipe-ground heat exchange rate would result in a decrease of the borehole length and hence, in the reduction of the installation costs and the return of investment period. Finally, an appropriate mechanical performance of the grouting material would provide the required stability of the borehole against ground loads, temperature fluctuations or harmful debonding problems [2]. Still, when it comes to the construction stage of the GSHP installation, highly flowable grouts are preferred to the detriment of materials fulfilling all those properties. This is because of the higher workability, which makes the pumping operation easier. Something similar happens with other applications, where grouts are required to have very good flow properties [3] along with other characteristics.

Bentonite is a well-known material widely used by drilling and geothermal energy related companies. Workability and low permeability are main advantages of this material, whereas low thermal conductivity and volumetric instability are probably the main drawbacks. Most of the authors deal with the thermal conductivity of bentonite-based grouts and mortars and the way this property can be enhanced by adding silica sand [4] or different forms of graphite $[5,6,7]$. The addition of these fillers resulted in higher conductivities of the tested grouts. As for cementitious grouts, the influence on their effective thermal conductivity was studied when silica sands [2,8,9,10,11], steel sands, steel grits or steel fibres [8] and steel slags [12] were used in different gradations. In all these cases, higher conductivities were obtained as compared to neat cement grouts, whereas potential borehole length reductions of $22-37 \%$ were estimated for a grout with a thermal conductivity three times higher instead of the neat cement $[9,13]$. mechanical behaviour. More specifically, infiltration tests and mechanical push out tests were developed in order to evaluate the sealing performance of the grouts and the bond quality at the grout-pipe interface $[2,14,15,16]$. Results from the tests showed the very low permeability of 
both the neat cement and cement-sand grouts themselves. However, the permeability increased when the same test was applied to grout-pipe specimens, probably due to the presence of pathways at the interface. On the other hand, a superior sealing quality was obtained for the cement-sand grout as compared to the neat cement grouts, what agrees with the higher mechanical bond strength measured for cement sand-grouts.

Durability is an indispensable requisite for grouting materials that might suffer from freezethaw and wet-dry loads during their lifetime. Freeze-thaw cycles are likely to occur when GSHP systems are not properly balanced and the winter heating loads are much larger than the summer cooling loads. As for the wet-dry cycles, they play a key role when the GSHP installations are located in areas with variable water tables. A severe damage due to any of these events could eventually result in an increase of the borehole thermal resistance and therefore, a decrease of the GSHP thermal performance. Likewise, this damage could also impact the environment.

According to $[14,15]$, the hydraulic conductivity of cement-sand grout/pipe specimens slightly increased as a result of applying wet-dry loads, whereas neat cement specimens critically cracked after the treatment. In this sense, the addition of steel fibres to cement-based grouts was shown to improve the cracking resistance of the material and mitigate the increase of permeability that wet-dry cycles involve [17]. As for the effect of freeze-thaw cycles, Erol and François [18] evaluated the influence of the permeability of silica-sand and calcite based grouts on their cracking resistance due to the thermal stress induced by freezing loads. Also, the effect of freeze-thaw cycles on the mechanical and thermal performance of cement-sand grout/pipe specimens was negligible as reported in [19]. Finally, the compressive strength of cementitious grout/pipe specimens exhibited certain decrease when $-5^{\circ} \mathrm{C} / 50^{\circ} \mathrm{C}$ cycles were applied [20].

In order to narrow the gap and consolidate the knowledge on this issue, the durability of four different grouting materials with high water/solid ratios for workability (pumping) purposes has been evaluated in this paper as a continuation of the research published in a previous one [21]. Thus, the suitability of these grouts has been discussed based on their thermal, mechanical and hydraulic behaviour both before and after extreme conditions in the form of wet-dry and freezethaw loads were applied.

\section{Materials and methods}

Along the research that made possible this paper, four different grouts consisting of Type I Portland cement, bentonite clay, silica sand and graphite flakes were considered as typical in 
the construction of GSHP installations. Proportions (by weight) of the solid fraction of the grouts are presented in Figure 1 whereas the composition including the mixing water as well as the corresponding water/solid (w/s) and water/cement (w/c) ratios are shown in Table 1. As can be seen in Figure 1, the grouts here analyzed have decreasing and increasing contents of cement and bentonite, respectively. As for the sand and graphite, grouts G1, G2 and G3 keep a similar global amount of these components (25\%), although G1 consists of sand only whereas in G2 and G3 both components exist that are distributed in the opposite way. While in G3 the use of bentonite is aimed to improve the plastic properties of the grout, the high content of the clay in G4 comes from the need of keeping the sand in suspension to avoid sedimentation.

According to this composition, the behavior of G1 was expected to be influenced by the higher amount of cement and the moderate (in this context) w/c and w/s ratios. Based on the cement content and the still moderate (when compared to G2) w/s ratio of G3, a comparable behaviour before the durability treatment should be expected from this grout despite the higher use of bentonite. As for G2, results should be cleary influenced by the much higher amount of mixing water used, which is linked to the extensive use of graphite as enhancing additive. Finally, the particular composition of G4, with a very high $\mathrm{s} / \mathrm{c}$ ratio and a extensive use of bentonite, should make a difference as compared to the other grouts.

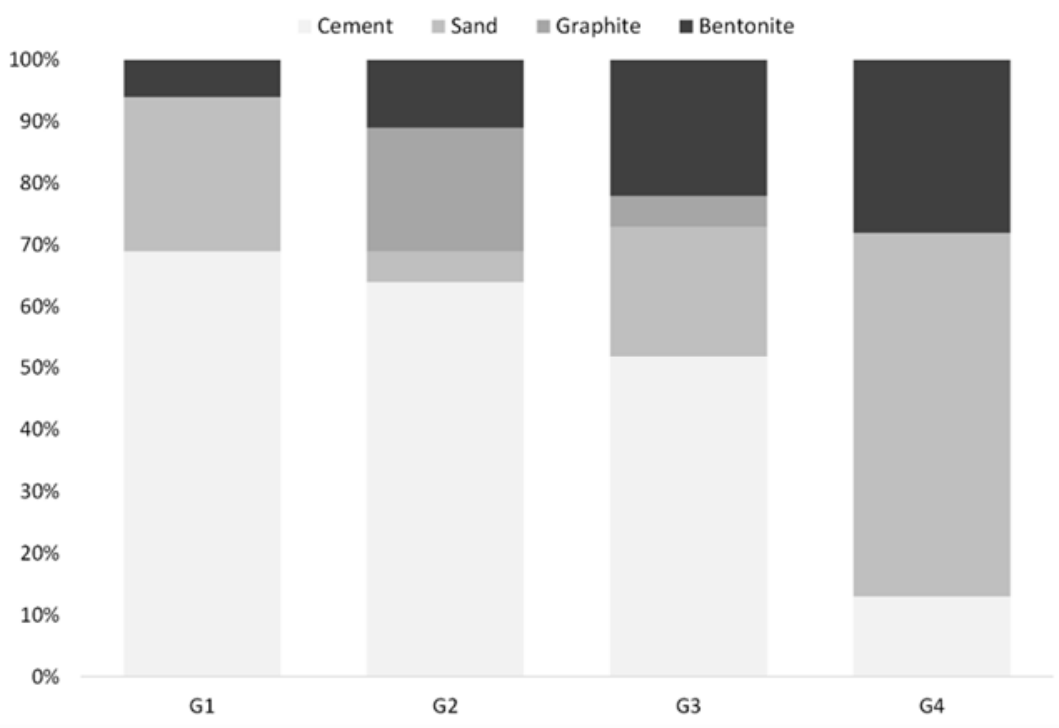

Figure 1. Proportions (by weight) of the solid fraction of the grouts considered for study.

116 For the characterization of the grouts at laboratory level, typical tests were performed according 117 to EN and ASTM standards: fresh and hardened density, water-accessible porosity, bleeding and Marsh Funnel (MF) viscosity. Results were as expected [21] and therefore, all the grouts were considered suitable for the durability assessment. 
Table 1. Composition (by weight) of the grouting materials including mixing water

\begin{tabular}{cccccccc}
\hline GROUT & $\begin{array}{c}\text { Cement } \\
\mathbf{( \% )}\end{array}$ & $\begin{array}{c}\text { Bentonite } \\
(\%)\end{array}$ & $\begin{array}{c}\text { Sand } \\
\mathbf{( \% )}\end{array}$ & $\begin{array}{c}\text { Graphite } \\
\mathbf{( \% )}\end{array}$ & $\begin{array}{c}\text { Water } \\
(\%)\end{array}$ & $\begin{array}{c}\mathbf{w} / \mathbf{s} \\
(\mathbf{k g} / \mathbf{k g})\end{array}$ & $\begin{array}{c}\mathbf{w} / \mathbf{c} \\
\mathbf{( k g} / \mathbf{k g})\end{array}$ \\
\hline $\mathbf{G 1}$ & 49 & 4 & 18 & 0 & 29 & 0.4 & 0.6 \\
$\mathbf{G 2}$ & 36 & 6 & 3 & 11 & 44 & 0.8 & 1.3 \\
$\mathbf{G 3}$ & 35 & 15 & 14 & 3 & 33 & 0.5 & 1.0 \\
$\mathbf{G 4}$ & 8 & 18 & 38 & 0 & 36 & 0.6 & 4.3 \\
\hline
\end{tabular}

121

For the preparation of the different grout specimens, a $750 \mathrm{~W}$ mortar mixer with variable speed was used. The power of this mixer was assumed high enough based on the fluid consistency of the grouts. Fresh grouts were cured for 48 hours under laboratory conditions. Following, molds were removed and the specimens were immersed in water at $20^{\circ} \mathrm{C}$ for 28 curing days. Finally, mechanical, thermal and hydraulic-infiltration tests were carried out on the grout specimens before and after they were subjected to repeated freeze-thaw and wet-dry cycles. One tailormade and two standard types of specimens were used to comply with the requirements of the different laboratory tests [21]: thin solid cylinders for the thermal conductivity tests; hollowed cylinders with one embedded HDPE pipe for the hydraulic tests; and a rectangular prism for the mechanical strength tests. Specific easy to cut and handle PVC molds were arranged for the first two types of specimens while standard metal molds were used for the third one.

Grout were exposed to 28 freeze-thaw cycles and up to 14 wet-dry cycles, lasting 24 hours and 9 days per cycle, respectively. For the first 8 hours of each freeze-thaw cycle, specimens were placed in a freezer at a temperature of $-10^{\circ} \mathrm{C}$, while for the last 16 hours they were placed in a water tank at ambient temperature $\left(+20^{\circ} \mathrm{C}\right)$. As for the wet-dry cycles, specimens were placed in a water tank at ambient temperature $\left(+20^{\circ} \mathrm{C}\right)$ for 7 days and then introduced in a drying oven at $40^{\circ} \mathrm{C}$ for the following 2 days. Four different tests were carried out on the grouting materials before and after the extreme loads were applied. Thermal conductivity values in accordance with the ASTM 5334-08 standard were obtained after 0, 7, 14, 21 and 28 freeze-thaw cycles and after 0,7 and 14 wet-dry cycles. Three measurements were taken with the TP02 probe of the Hukseflux TPSYS02 system from each of the three specimens used per type of material and load applied. This Non-Steady-State Probe (NSSP) method, also known as transient line source, with conductivity and temperature ranges of 0.1 to $6 \mathrm{~W} / \mathrm{mK}$ and -55 to $180{ }^{\circ} \mathrm{C}$, respectively, complies with the standard followed. As for the mechanical tests, values of compressive and flexural strength of the hardened grouts were measured (EN 1015-11) at 0 and 14 wet-dry cycles and at 0 and 28 freeze-thaw cycles, although the fact that the specimens became seriously cracked during this period also influenced the final number of cycles. Flexural and compressive 
strengths were determined as the mean values of the three and six specimens tested, respectively. Likewise, ultrasonic pulse velocity through the grouts was measured with a CSI Concrete Tester CCT-4 in order to monitor existing manufacturing defects or the rise of cracks after the durability treatment. To calculate it, the length of the specimens was divided by the time taken by the pulse to get through them, which was measured before and after the application of 14 wet-dry cycles and 28 freeze-thaw cycles.

The loss of grout-pipe bond quality was evaluated as related to the hydraulic conductivity of the grout-pipe system, which was measured at $0,7,14,21$ and 28 freeze-thaw cycles and at 0 , 1 and 7 wet-dry cycles. An increasing permeability of the grout-pipe system as a result of the cycles applied would be linked to the raise of cracks or defects within the grout-pipe interface, which might lead to issues such as the decrease of the GSHP efficiency or cross-contamination of aquifers. To calculate the hydraulic conductivity of the grout-pipe specimens, variable head permeability tests were performed by means of a basic tailor-made device with a pipe on top that made possible to supply a water column to the specimen [21]. The water would be restricted to either passing through the grout itself or the grout-pipe interface. The value of hydraulic conductivity was determined according to the expression in [21] and is based on the time taken by the water to drop a certain length of pipe. Three specimens per type of grout and durability treatment were tested.

\section{Results and Discussion}

\subsection{Thermal conductity}

Results of thermal conductivity of the grouts before and right after they were exposed to 14 wet-dry and 28 freeze-thaw cycles, are displayed in Figures 2 and 3 for comparison purposes. As it can be seen, values of thermal conductivity before the application of the extreme loads are lower than expected if the use of conductive fillers such as silica sand or graphite is considered $[2,5,7]$. This is because of the synergistic effect of the excess of mixing water and the increasing use of bentonite. Thus, along with the very well-known poor thermal properties of the bentonite, the high w/s ratios normally used in common grouts for workability purposes would eventually result in higher porosities and hence, in lower thermal conductivities [8,18]. As for the evolution of this parameter with time when extreme loads are applied, Figures 2 and 3 shows how the thermal conductivity of the grouts seems not to be much influenced by the application of wetdry and freeze-thaw loads, respectively, and only the high amount of mixing water in G2 seems to affect, but to a minor extent. 


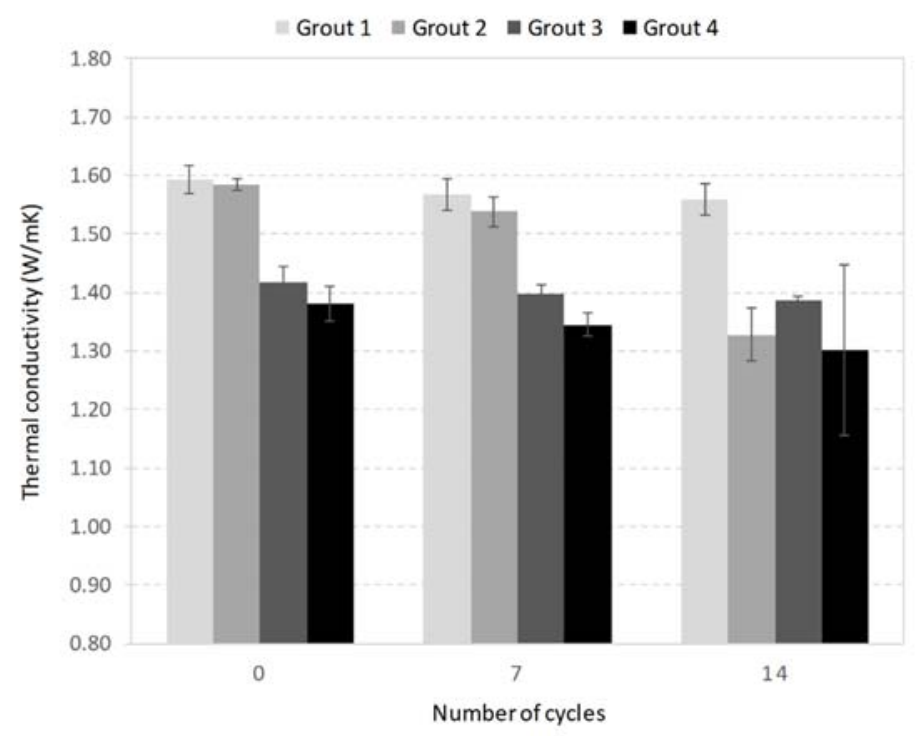

Figure 2. Evolution of the thermal conductivity of grouts when exposed to wet-dry cycles.

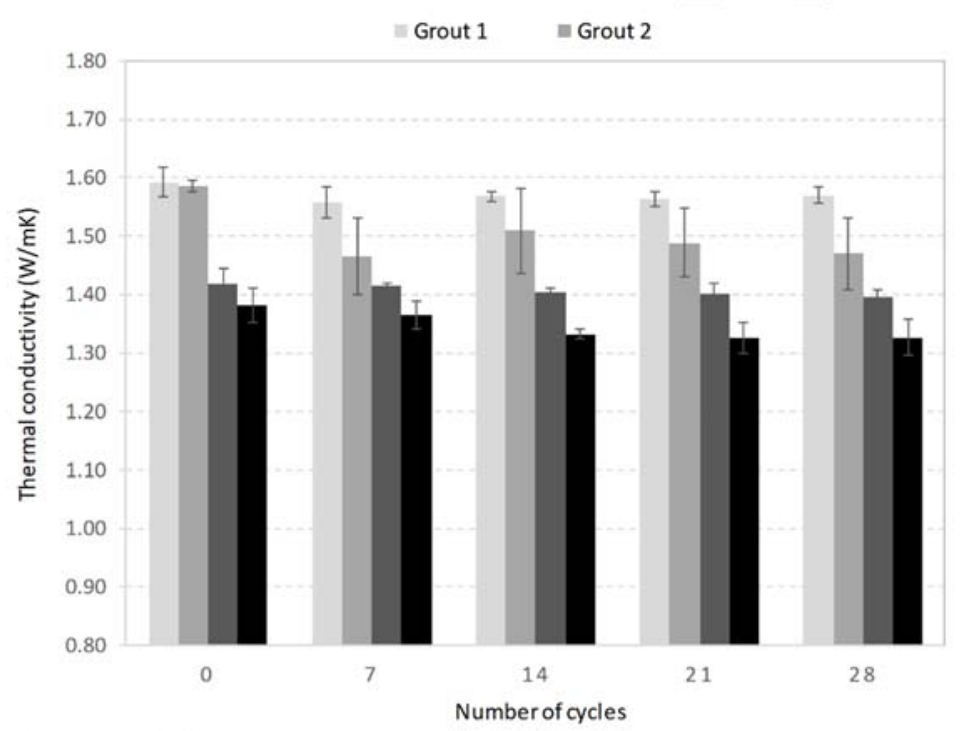

Figure 3. Evolution of the thermal conductivity of grouts when exposed to freeze-thaw cycles.

Thus, although the specimens of some grouts actually suffered from some damage (Figure 4), especially after being subjected to freeze-thaw cycles, the use of casings helped to prevent their critical deterioration whereas the presence of remaining water in between the cracks partially restrained the expected thermal performance decay. Note that the use of casings does not mean significant alteration in the analysis of results because the grout is naturally confined by the ground in GSHP installations. In this sense, Figure 5 shows what the relation between the w/s ratio and the resulting decrease of the thermal conductivity after the two durability cycles is like. It can be seen that for low $\mathrm{w} / \mathrm{s}$ ratios the retained conductivity is close to $100 \%$ no matter the durability process considered, and only when the ratio increases 
the percentage of retained conductivity starts to drop and the differences between the trends of both curves come up. The equations of the fitted curve are only illustrative, as a higher number or w/s ratios should have been tested in order to properly validate them.

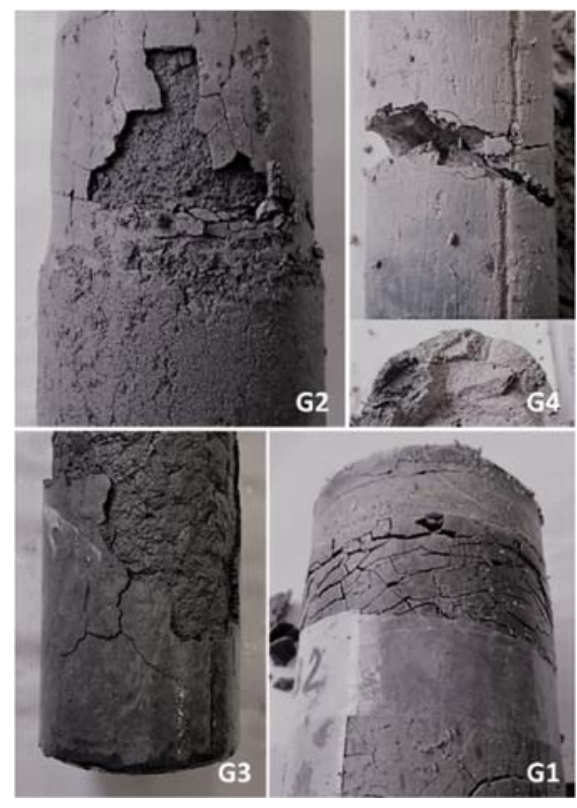

Figure 4. Damage in specimens after 14 wetdry cycles (G2) and 28 freeze-thaw cycles.

\subsection{Mechanical performance}

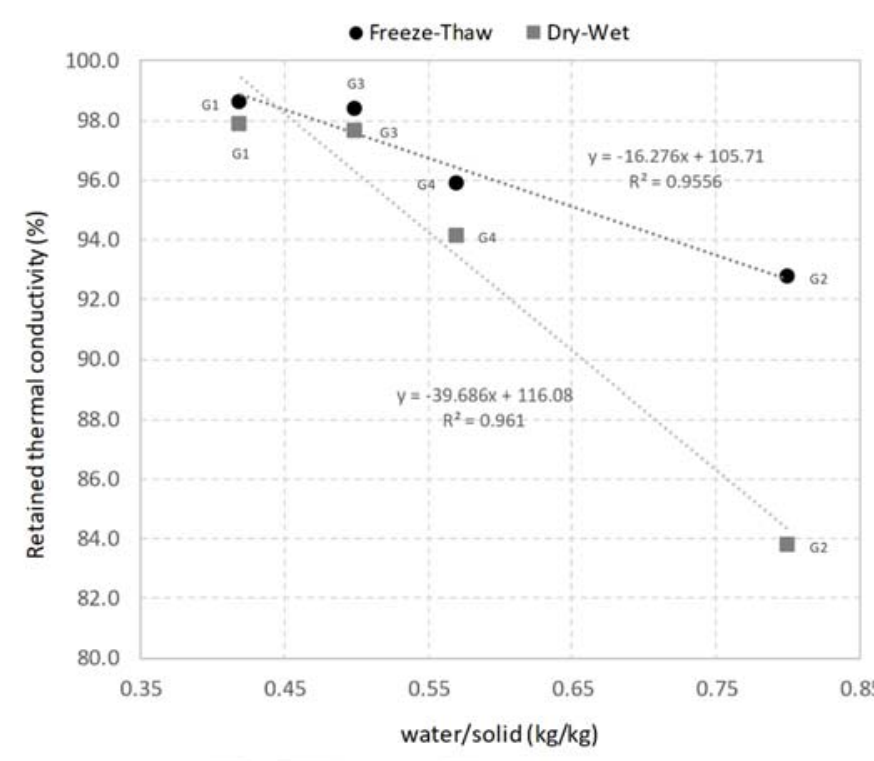

Figure 5. Influence of the w/s ratio on the decrease of the thermal conductivity after the durability treatments.

Results of the tests done to the specimens after the 28 days curing period are shown in Figure 6. As expected, low values of compressive and flexural strengths were obtained.
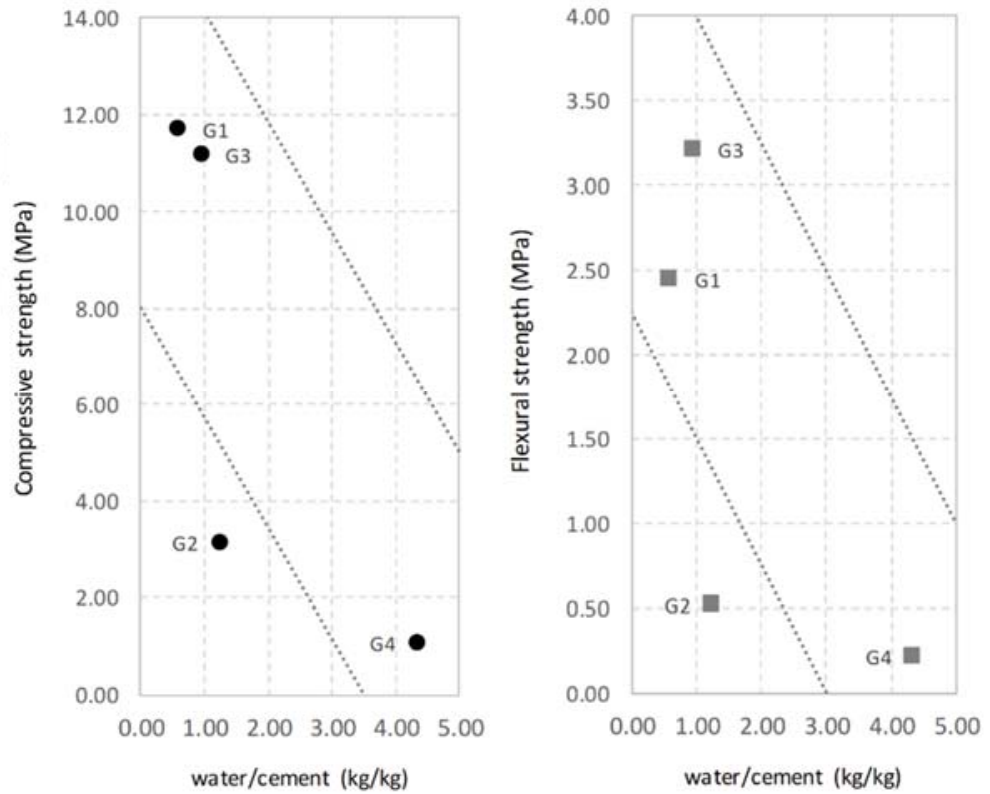

Figure 6. Compressive and flexural strengths of grouts as a function of their w/c ratios. 
Values of compressive strength ranging between 1.1 and 11.7 MPa have been obtained in this research, whereas values of up to $36 \mathrm{MPa}$ were reached by more conventional mortars with less remarkable flow properties [17]. Also, the w/c ratio used for the design of the grouting materials is very relevant when their mechanical performance is concerned. In this sense, the higher values of mechanical resistance of grouts with lower w/c ratios as well as the tendency of this parameter to decrease with increasing w/c ratios are illustrated in Figure 6, which is in accordance with the literature [20,22]. The deviation of G2 from the expected tendency is probably due to the much higher amount of mixing water used, which is on account of the great amount of graphite added to this admixture. The low quantity of sand should also affect. All in all, although certain mechanical capacity is always required to guarantee the stability of the borehole against ground loads, the structural role is not between the requisites of these geothermal grouting materials, which makes all of them suitable for being used in most GSHP applications.

Regarding the durability of the grouts, the results of the tests performed after the wet-dry cycles (Figure 7) clearly state that there is hardly any harmful influence of this specific treatment on their mechanical performance. The non-saturation of the specimens during the time they were submerged might have had an influence on this lack of mechanical deterioration. Therefore, although some differences can be observed such as the little increase in the resistance of grouts with higher w/c and w/s ratios or the lack of substantial change of grouts with more moderate ratios, this has been assumed to be due to the uncertainty of the testing procedure or the intrinsic behaviour of the materials.

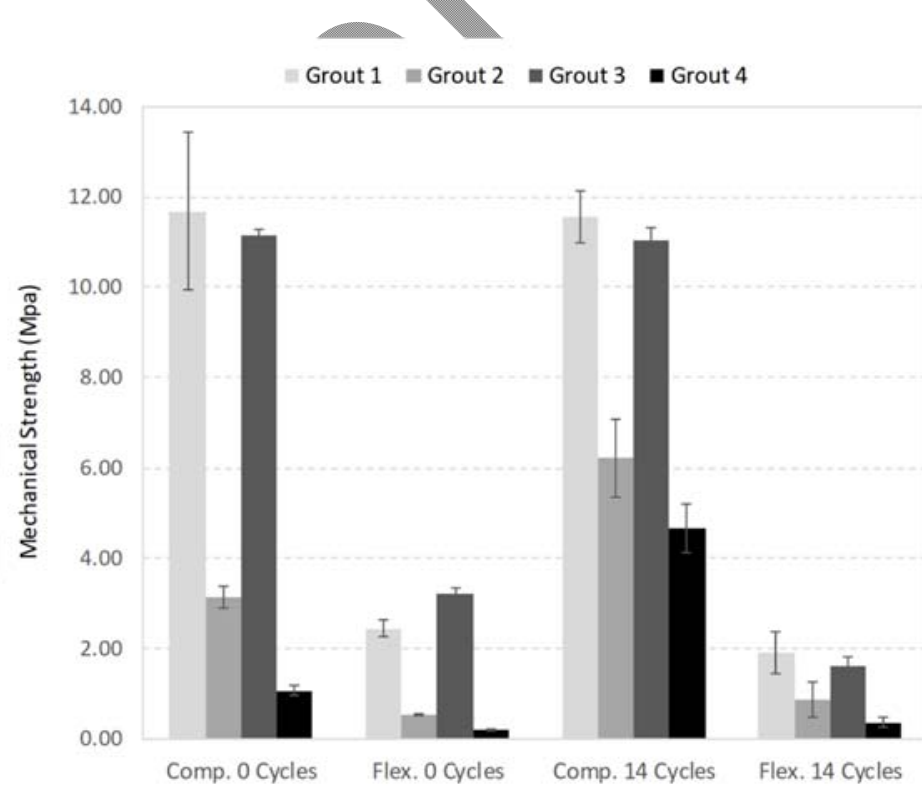

Figure 7. Evolution of the mechanical strength of grouts when exposed to wet-dry cycles.

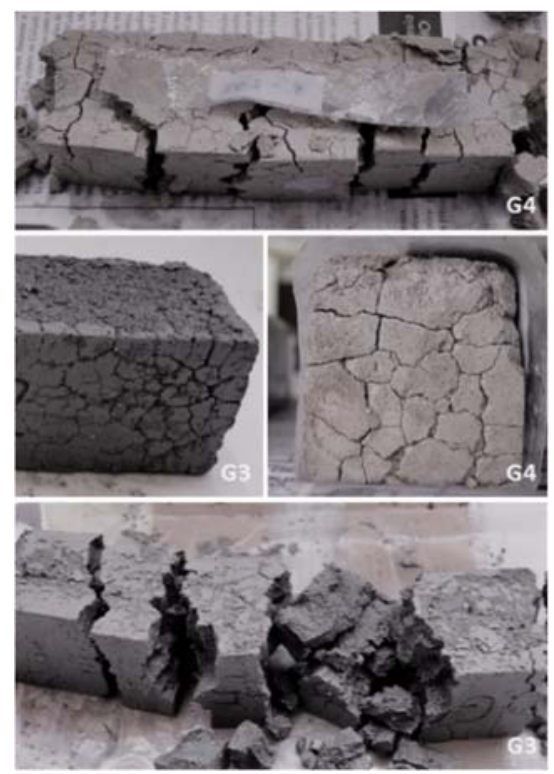

Figure 8. Critical damage in specimens for mechanical testing after 7 freeze-thaw cycles. 
On the other hand, no conclusive results were obtained from the freeze-thaw treatment due to

210 the freezing-induced stress that resulted in the formation of fatal cracks on the specimens only 211 after the first 5 to 7 cycles (Figure 8).

212 Testing was impossible and their freeze-thaw strength was thus considered negligible, as it was 213 with the simpler neat cement grouts tested in [19], whereas other more conventional mortars 214 are not so critically affected $[14,20]$ by this treatment. Accordingly, the use of water in excess 215 for workability purposes turned out to be extremely harmful for the durability of the grouts here 216 considered. Therefore, their use should be carefully considered in GSHP systems with 217 unbalanced thermal designs or very demanding operational conditions in winter time. In general, 218 not only the decrease of the stability of the borehole should be taken into account (this matters, 219 but in a lesser extent), but also the rise of less critical cracks that would eventually lead to 220 increasing borehole thermal resistance or environmental impacts.

221 A similar analysis can be done based on the results of the ultrasonic pulse velocity tests (Figure 222 9). The very small variations obtained (under 7\%) do not allow to infer a noticeable change in 223 the internal structure of the grout specimens after being exposed to 14 wet-dry cycles, especially 224 if the accuracy of the testing equipment is considered.

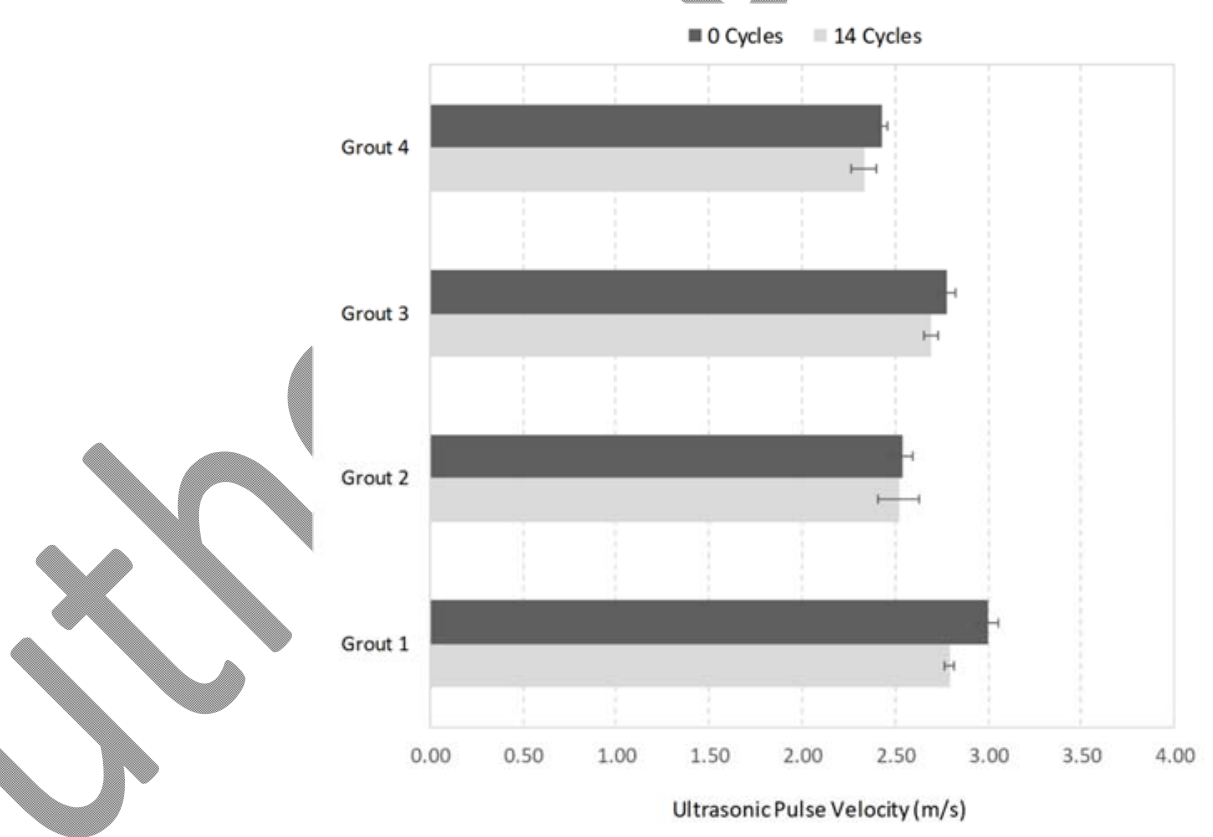

Figure 9. Variation of the utrasonic pulse velocity through the grouts before and after the wet-dry treatment.

\subsection{Grout-pipe permeability}

227 A study was also done about the hydraulic conductivity or permeability of the grout-pipe system before and after the durability treatments. Based on the magnitude of the data collected during 
the tests and the variations occurred, logarithmic axis have been used in the following graphs for the proper analysis of those results. The bar chart in Figure 10 shows the evolution of this parameter when the wet-dry cycles are applied.

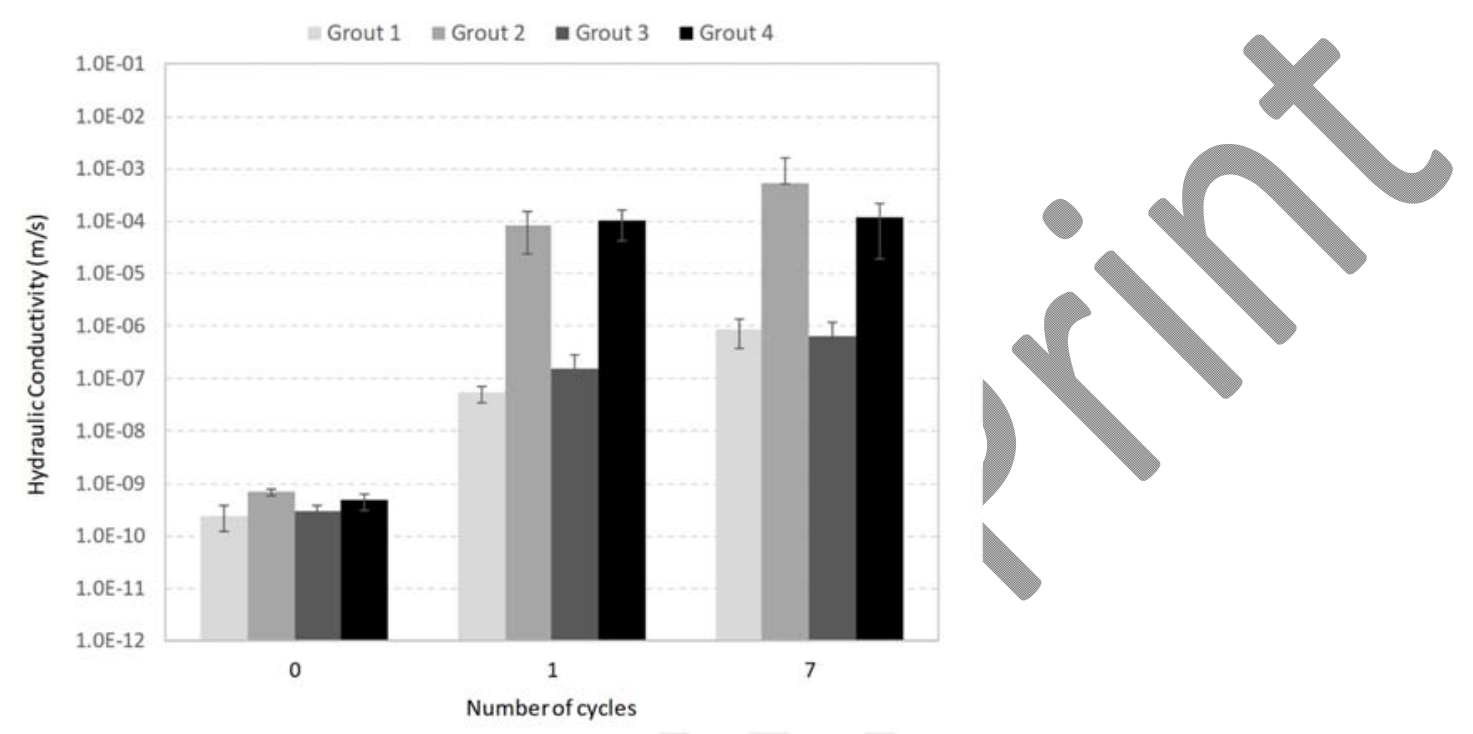

Figure 10. Evolution of the hydraulic conductivity of the grout-pipe system when exposed to wet-dry cycles.

This chart shows that the permeability of all the grout-pipe specimens right after the 28 days curing period is very low no matter their composition or the amount of water used for their manufacturing. The results are close or even slightly lower to those measured in $[2,20]$, which means that a suitable sealing capacity was here achieved in spite of the different methodological approach proposed by those researchers.

Regarding the results of durability, the values of hydraulic conductivity obtained at the end of the treatment showed an important increase of the permeability of all the grout-pipe specimens, significantly higher than in other representative research projects [14]. This is especially critical for the grouts G2 and G4, with much higher w/s ratios, where the hydraulic conductivity drop is on the order of $10^{5}$ (Figure 11). The shear stress originated in the grouts because of the higher thermal expansion coefficient of the HDPE pipe, might have caused this serious loss of groutpipe bond quality as well as the rise of cracks. As for the other grouts, the drop is not so severe, with remaining hydraulic conductivities on the order of $10^{-7}$.

246 On the other hand, considering the close values of permeability achieved by G1 and G3 after 247 the treatment, the extra amount of bentonite in G3 seems to have had hardly any effect or 248 otherwise the treatment might not have been so demanding as to make this component critical. 249 Based on the fact that most of this drop occurred during the first cycle, after which the values of permeability suffered very little change, and considering also the extreme loads applied 

of a conventional GSHP installation.

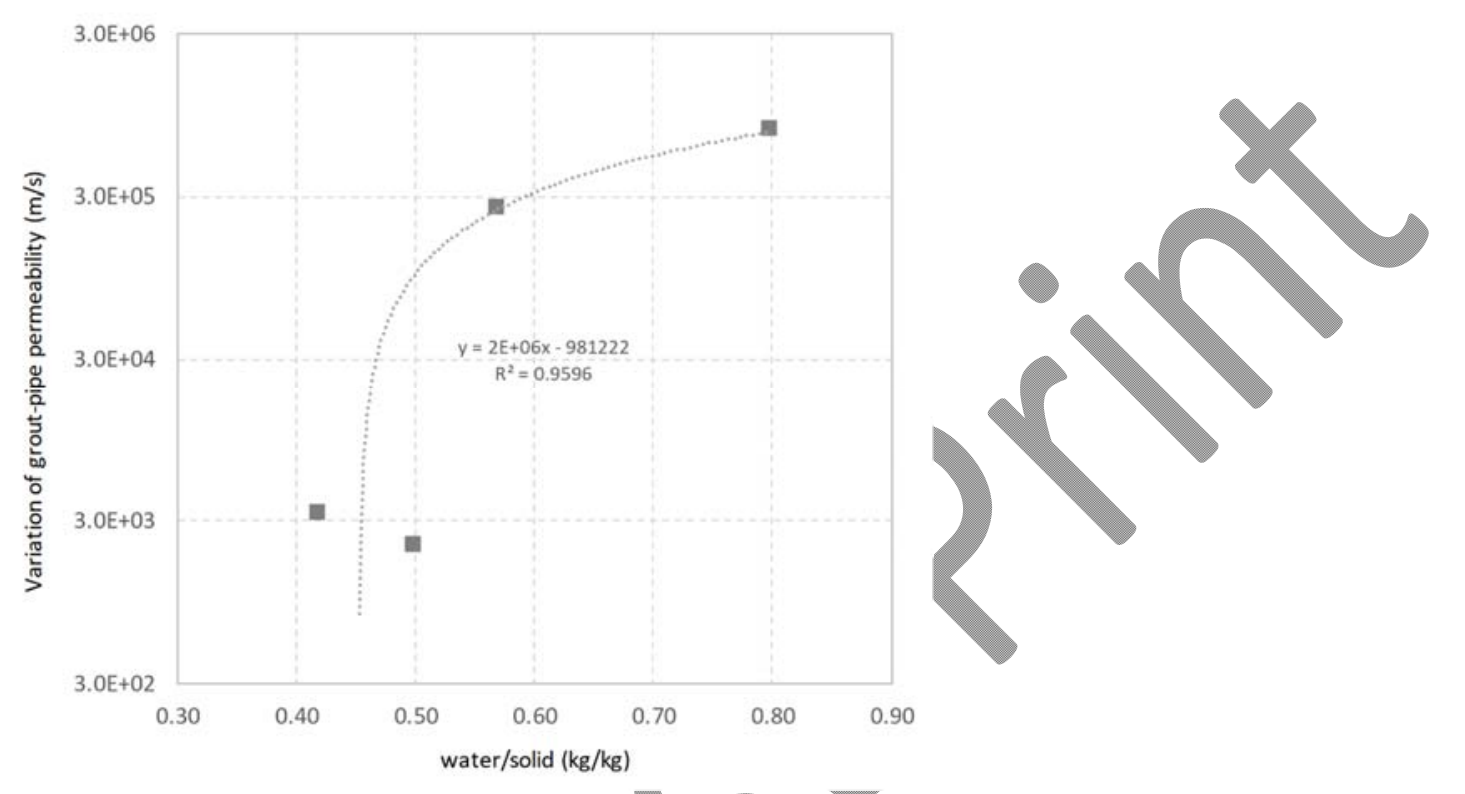

Figure 11. Influence of the mixing water on the permeability of the grout-pipe specimens after the wet-dry cycles.

In Figure 12, the grout-pipe permeability of the different specimens has been represented as a function of the initial mechanical resistance of the materials. As can be seen from the graph, an accurate correlation exists between both parameters, just like happened (in a lesser extent) when these grout-pipe specimens were subjected to heating-cooling cycles in a previous stage of the research [21]. Thus, even though the shear strength has not been determined, this graph actually illustrates how the materials with higher compressive and flexural strength seems to better withstand the stress created as a result of the different expansion coefficient of pipes and grouts.

Finally, the evolution of the hydraulic conductivity of the grout-pipe system when exposed to freeze-thaw cycles is shown Figure 13. Just like it was done in previous treatments, the number of cycles applied depended on the level of deterioration reached by the materials tested. In this case, as for the wet-dry cycles, the treatment finished when most of the grout-pipe specimens reached a critical condition in terms of permeability. According to this chart, at the time of finishing the freeze-thaw treatment, the variation on average of the permeability of the groutpipe specimens was rather higher than for the former treatment. This is because unlike with the wet-dry loads, from which only those grouts with highest $\mathrm{w} / \mathrm{s}$ and $\mathrm{w} / \mathrm{c}$ ratios suffered severe damage, all the grouts after the freeze-thaw treatment have reached a critical situation in terms of sealing capacity no matter the amount of mixing water used. Regarding grouts G1 and G3, at the end of the durability treatment a difference of one order of magnitude existed between them. The flexible sealing properties provided by the extra content of bentonite in G3 might 
274 thermal expansion coefficients of grout and pipe.

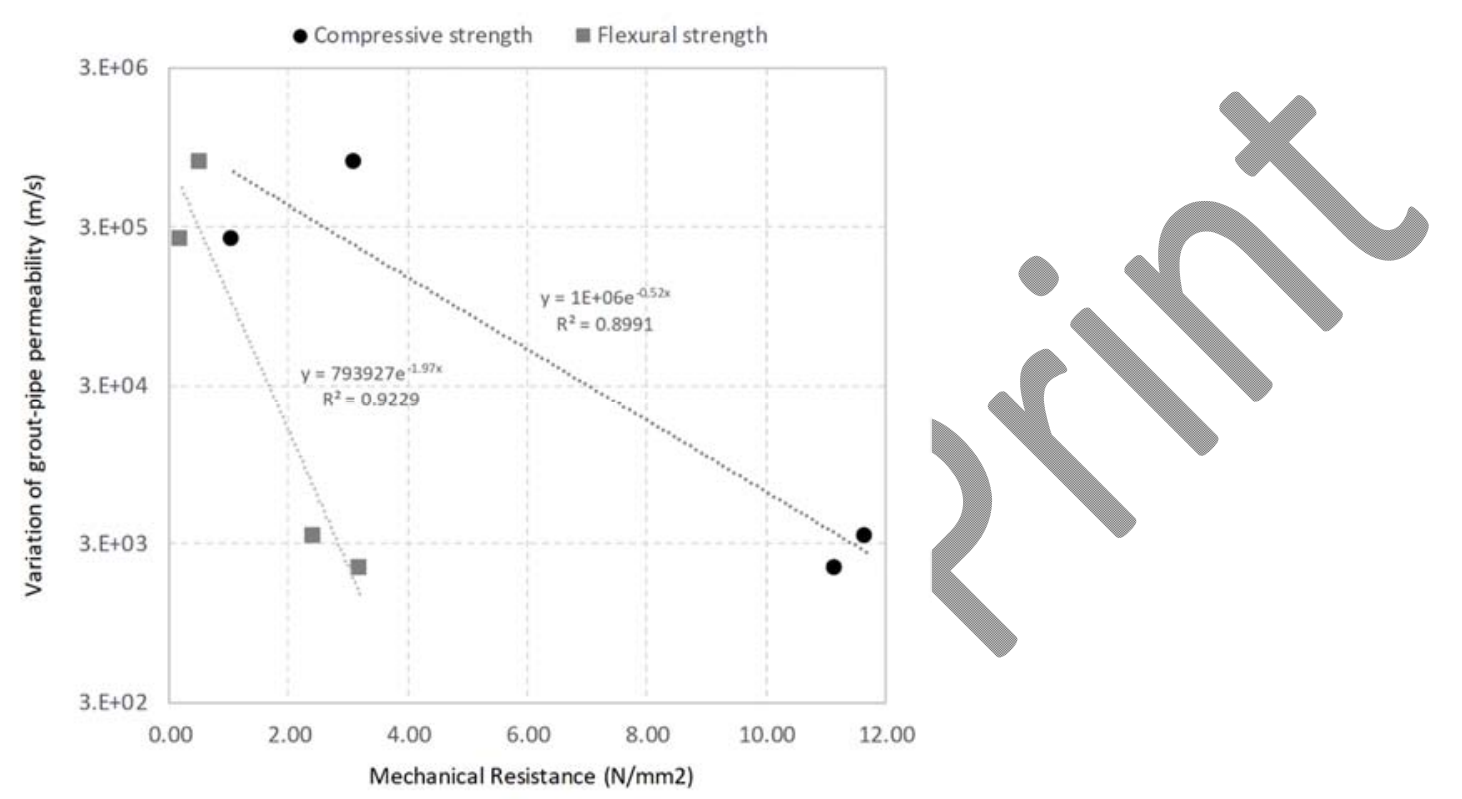

Figure 12. Variation of the grout-pipe permeability versus initial mechanical resistance of the grouts.

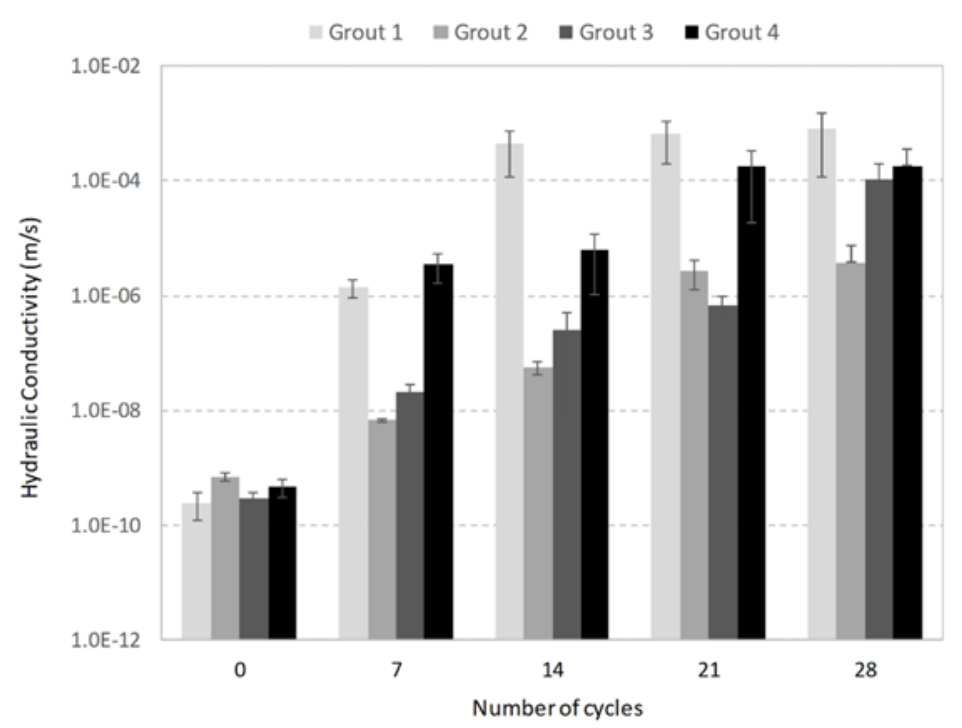

Figure 13. Evolution of the hydraulic conductivity of the grout-pipe system when exposed to freeze-thaw cycles.

277 The damage suffered by these four grouts, whose workability was sought by means of using a 278 high excess of mixing water, contrasts with the lack of significant impact of the freeze-thaw 279 treatments in other authors' research [14,20], where more conventional w/c ratios were used. 280 Considering their important goal as a barrier against contamination of aquifers, the use of grouts 281 whose grout-pipe bond quality is cleary affected by extreme loads, should be restricted to GSHP 282 installations with moderate potential environmental risks. 


\section{Conclusions}

284

285

In this paper, four types of grouting materials with improved workability by means of using an excess of water for their design have been characterized before and after being subjected to a double durability treatment based on the application of extreme wet-dry and freeze-thaw cyclic loads. The following conclusions can be remarked as a result of the analysis previously done:

- The values of thermal conductivity, mechanical performance (compressive and flexural strength) and sealing capacity of the grouting materials after the 28 days curing period, are influenced by the amount of mixing water used. Thus, these parameters decrease as the $\mathrm{w} / \mathrm{s}$ (and $\mathrm{w} / \mathrm{c}$ ) ratio of the four grouts increases. The increasing use of bentonite would have also contributed to the low-medium values of conductivity.

- The thermal conductivity of the grouting materials with low w/s ratios is poorly affected by both durability treatments, whereas for the highest ratios the loss of thermal conductivity starts to raise as well as the differences between wet-dry and freeze-thaw treatments. Nevertheless, the variations measured were always lower than $16 \%$, which eventually make the grouts suitable in terms of thermal performance for GSHP systems with average operational requirements.

- The limited differences existing in terms of the mechanical performance of the grouting materials before and after being subjected to wet-dry cycles might not be related to the durability treatment but to the uncertainty of the testing procedure. On the contrary, the compressive and flexural strength of these grouts against freeze-thaw cycles have been considered negligible according to the critical stress-induced cracks appeared within the specimens.

- The increase of the hydraulic conductivity suffered by the grout-pipe specimens when subjected to wet-dry cycles, seems to be dependent (on a certain extent) on the amount of mixing water used for the manufacturing of the grouting materials and hence, on their mechanical performance after the 28 days curing period. Thus, grout-pipe specimens with lower w/s ratios were able to keep a suitable sealing capacity, whereas the remaining materials, with highest $\mathrm{w} / \mathrm{s}$ and $\mathrm{w} / \mathrm{c}$ ratios, suffered a critical increase of the grout-pipe permeability.

- In the context of this research and based on the fact that both durability treatments were applied until critical degradation of some of the grouts involved, the freeze-thaw treatment has resulted to be the most harmful in terms of the integrity of the type of grouts here studied. On the other hand, the drying process has resulted to be more 
unfavorable for the thermal performance of the GSHP installations.

Therefore, as a general conclusion, grouts with high amount of mixing water for workability purposes can be used in GSHP systems as long as the water/solid ratio is within a certain limit and regular operational requirements and environmental conditions are considered.

\section{Acknowledgements}

The authors wish to express their gratitude to the Ministry of Economy and Competitiveness which funded this study within the Spanish National Plan for Scientific and Technical Research and Innovation (INNPACTO program) through the research project IPT-2011-0877-920000. The authors are also grateful to all the organizations and companies participating in this project: Sacyr Industrial, Universidad Politécnica de Madrid and Cype.

\section{References}

[1] Omer, A.M. Energy and Environment: Applications and Sustainable Development. British Journal of Environment \& Climate Change, 2011, 1(4): 118-158. DOI: 10.9734/BJECC/2011/480

[2] Allan, M.L. Materials characterization of superplasticized cement-sand grout. Cement and Concrete Research, 2000, 30 (6), pp. 937-942. DOI: 10.1016/S0008-8846(00)00275-1

[3] Güllü, H. On the Viscous Behavior of Cement Mixtures with Clay, Sand, Lime and Bottom Ash for Jet Grouting. Construction and Building Materials, 2015, 93, pp. 891-910. DOI: 10.1016/j.conbuildmat.2015.05.072

[4] Lee, C., Lee, K., Choi, H. and Choi, H.-P. Characteristics of thermally-enhanced bentonite grouts for geothermal heat exchanger in South Korea. Science China Technological Sciences, 2010, 53 (1), pp. 123-128. DOI: 10.1007/s11431-009-0413-9

[5] Delaleux, F., Py, X., Olives, R. and Dominguez, A. Enhancement of geothermal borehole heat exchangers performances by improvement of bentonite grouts conductivity. Applied Thermal Engineering, 2012, 33-34 (1), pp. 92-99. DOI: 10.1016/j.applthermaleng.2011.09.017

[6] Erol, S. and François, B. Thermal, hydraulic and mechanical performances of enhanced grouting materials for borehole heat exchanger. Coupled Phenomena in Environmental Geotechnics Proceedings of the International Symposium, ISSMGE TC 215, 2013, pp. 491-499.

[7] Erol, S. and François, B. Efficiency of various grouting materials for borehole heat exchangers. Applied Thermal Engineering, 2014, 70 (1), pp. 788-799. DOI: 10.1016/j.applthermaleng.2014.05.034 
[8] Allan, M.L. Preliminary study on improvement of cementitious grout thermal conductivity for geothermal heat pump applications. Department of Applied Science, Brookhaven National Laboratory, New York, 1996.

[9] Allan, M.L. Thermal conductivity of cementitious grouts for geothermal heat pumps. Progress Report FY 1997. Department of Applied Science, Brookhaven National Laboratory, New York, 1997.

[10] Allan, M.L. Quality Control and Troubleshooting for Grouts Used with Geothermal Heat Pumps. Proceedings World Geothermal Congress. Melbourne, Australia, 19-25 April 2015.

[11] Kim, D., Kim, G. and Baek, H. Thermal conductivities under unsaturated condition and mechanical properties of cement-based grout for vertical ground-heat exchangers in Korea - A case study. Energy and Buildings, 122 (2016), 34-41. DOI: 10.1016/j.enbuild.2016.02.047

[12] Borinaga-Treviño, R., Pascual-Muñoz, P., Castro-Fresno, D. and Del Coz-Diaz, J.J. Study of different grouting materials used in vertical geothermal closed-loop heat exchangers. Applied Thermal Engineering, 2013, 50 (1), pp. 159-167. DOI: 10.1016/j.applthermaleng.2012.05.029

[13] Allan, M.L. and Kavanaugh, S.P. Thermal conductivity of cementitious grouts and impact on heat exchanger length design for ground source heat pumps. HVAC\&R Research, 1999, 5 (2), pp. 87-98. DOI: $10.1080 / 10789669.1999 .10391226$

[14] Allan, M.L. and Philippacopoulos, A.J. Thermally conductive cementitious grouts for geothermal heat pumps. Progress Report FY 1998. Department of Applied Science, Brookhaven National Laboratory, New York, 1998.

[15] Allan, M.L. and Philippacopoulos, A.J. Properties and performance of cement-based grouts for geothermal heat pump applications. Final Report FY 1999. Department of Applied Science, Brookhaven National Laboratory, New York, 1999.

[16] Allan, M.L. and Philippacopoulos, A.J. Performance characteristics and modelling of cementitious grouts for geothermal heat pumps. Proceedings World Geothermal Congress 2000, Kyushu - Tohoku, Japan.

[17] Berndt, M.L. Strength and permeability of steel fibre reinforced grouts. Construction and building materials, 2010, 24 (9), pp. 1768-1772. DOI: 10.1016/j.conbuildmat.2010.02.011

[18] Erol, S. and François, B. Freeze damage of grouting materials for borehole heat exchanger: Experimental and analytical evaluations. Geomechanics for Energy and the Environment, 2016, 5, pp. 29-41. DOI: 10.1016/j.gete.2015.12.002

[19] Borinaga-Treviño, R., Pascual-Muñoz, P., Calzada-Pérez, M.A. and Castro-Fresno, D. Freeze-thaw durability of cement-based geothermal grouting materials. Construction and building materials, 2014, 
378 [20] Park, M., Min, S., Lim, J., Choi, J.M. and Choi, H. Applicability of cement-based grout for ground 379 heat exchanger considering heating-cooling cycles. Science China Technological Sciences, 2011, 54 380 (7), pp. 1661-1667. DOI: 10.1007/s11431-011-4388-y

381 [21] Indacoechea-Vega, I., Pascual-Muñoz, P., Castro-Fresno, D. and Calzada-Pérez, M.A. 382 Experimental characterization and performance evaluation of geothermal grouting materials subjected 383 to heating-cooling cycles. Construction and building materials, 2015, 98, pp. 583-592. DOI: 384 10.1016/j.conbuildmat.2015.08.132

385 [22] Chen, X., Wu, S. and Zhou, J. Influence of porosity on compressive and tensile strength of cement 386 mortar. Construction and building materials, 2013, 40, pp. 869-874. DOI: 387 10.1016/j.conbuildmat.2012.11.072 